\title{
Esophageal Mucositis
}

National Cancer Institute

\section{Source}

National Cancer Institute. Esophageal Mucositis. NCI Thesaurus. Code C79575.

An inflammatory process affecting the mucous membrane of the esophagus. 